\title{
A Critical Reflection on the Ethically Cared Facilities and Equipment for School and Children: A Transition from the Cold to the Warm
}

\author{
Fei Wang \\ Guangzhou Educational Infrastructure and Equipment Center, Guangzhou, China
}

\author{
Email address: \\ wangfei1356531@126.com
}

To cite this article:

Fei Wang. A Critical Reflection on the Ethically Cared Facilities and Equipment for School and Children: A Transition from the Cold to the Warm. Science Journal of Education. Vol. 9, No. 5, 2021, pp. 177-180. doi: 10.11648/j.sjedu.20210905.15

Received: September 28, 2021; Accepted: October 22, 2021; Published: October 30, 2021

\begin{abstract}
A problem in application of educational facilities and equipment exists in schools that people tend to regard such technology from a cold view and neglect the ethical care for the schools and children. Influenced by a cold cognition from the industrial times, people in education community tend to consider the application of facilities and equipment as technological issues, paying less attention to the young people for their healthy physical and mental growth and potential invasion of children's privacy. The cases of such violence or impingement of school children are happening frequently though not on negative purposes from the users and producers of educational facilities and equipment. The reason is apparent because people involved in these processes are not ethically trained, and they are unaware of ethical considerations in designing and applying the technical stuff. This article identified salient problems and raised countermeasure to remind the colleagues: (1) The application of educational facilities and equipment should conform to the real needs of teachers and students. (2) The educational equipment should fit users' convenience and avoid cumbersome. Educational facilities and equipment should reflect its original nature that it is human beings who are the masters. (3) Educational facilities and equipment should take the role of service for education for goal-oriented assistance for the appropriate teaching and learning.
\end{abstract}

Keywords: Ethics, Education, Facilities and Equipment, Children, School

\section{Introduction}

\subsection{Ethical Care for Educational Facilities and Equipment}

Educational facilities and equipment are two aspects including hardware and software used in the process of education and teaching activities for achieving educational purposes. That is, they cover not only instruments and equipment in the hardware form, but also programmed and digital resources in software form. Whether it is in the form of hardware or programs and digital resources in the form of software, there exists a problem. They are generally regarded as something cold and inanimate, things without care for students' feelings, and are external impositions to students. It has been a tendency for people in educational community to regard them as machines since industrial time. Even if today in the information society, people are still accustomed to using a mechanical mind or "cold cognition" to view their functions and usage in educational and teaching practice.

These positions and viewpoints have caused serious troubles in school practice. Mechanized, information-based, and new products of the robot age are causing various kinds of violations to students and teachers. What should have played an auxiliary and supportive role has become something that dominates and governs schools and students. Their supporting role has on the way that is just opposite. It is a big irony of educational facilities and equipment on modern education.

In this regard, we need to put forward profound criticism and reflect on the value, function, advantages and disadvantages of the educational facilities and equipment we are using in the process of education and teaching. Specifically, we need to raise some questions from the standpoint of ethics for our colleagues to think about and improve the existing problems in education and teaching practice.

In short, educational facilities and equipment call for an ethical view. Our point is that educational facilities and 
equipment must adhere to ethics, regrading students as the center of school and aim at educating people on an ethic basis, and actively reflecting on the reasons, meanings and forms of educational facilities and equipment, so as to promote the active growth and coordinated development of teachers and students in the application of equipment.

Furthermore, when any object becomes a tool, the designer should give it a soul, so that it has a vivid life and a fare mission, with a humanist orientation. Ethics can shed light as a beacon on users, make tools move from negative to positive, and make tools glow with educational significance and enthusiasm.

And this is the topic to make educational facilities and equipment realize a transition from the cold use to the warm assistance.

\subsection{Related Definitions}

What is ethics? In Chinese, the two Characters 伦理 (ethic) mean the moral principle of humanist relations involving customs and criterion for people to get along with each other. It emphasizes the relationship between people and the rules for dealing with these relationships.

There are various interpretations concerning the definition of ethics.

According to Merriam-Webster's Dictionary, ethics is defined as "the discipline dealing with what is good and bad and with moral duty and obligation ${ }^{1}$.

Ethics generally refers to a series of concepts guiding human behaviors. It is a philosophical reflection on moral phenomena from the conceptual point of view. It contains not only the behavioral norms in dealing with the relationships between people, society, and nature, but also the profound truth of standardizing behaviors based on certain social contextual conditions.

Ethics also refers to the norms of order pertaining to the relationships and behaviors among people society and the state in human society.

Ethics is thus regarded as the social behavior norms recognized explicitly or acquiesced implicitly in people's minds. Ethics adjusts the relationship between people, but the scope of its adjustment includes the category of the whole society. There is a strong internal connection and correlation with management ethics. On the one hand, management activities are a form of human social activities, which of course cannot be separated from the normative role of ethics. To discuss further, ethics means various moral norms for people to get along with each other. Ethics is a theory about the origin and development of morality, the code of conduct and the obligations between people ${ }^{2}$.

Broadly speaking, educational ethics is a new area of study in the field of education. It is a comprehensive subject that considers educational value and behavioral orientation from the perspective of human relations as well as rational thinking. It involves educational sciences and ethics, and is a philosophical discipline derived from these two disciplines

\footnotetext{
${ }^{1}$ https://www.merriam-webster.com/dictionary/ethics

${ }^{2}$ https://baike.baidu.com/item/\%E4\%BC\%A6\%E7\%90\%86/538?fr=aladdin
}

mentioned above. Its main purpose is to explore the educational actions, relationships, values, moral issues, rule orientations, responsibilities, and professional rules.

It seems that the ethical issues of educational facilities and equipment must be concerned with the following relations which connect educational facilities and equipment to national strategy, social core values, school development and curriculum, classroom, teachers, and students. Finally, there is a close even high-stakes connection with companies producing facilities and equipment for schools.

Put it simply, the ethical issues of educational facilities and equipment involve various decisions, which need to be guided by beliefs and ideals and supported by criticism and reflection.

What we should ask is that the educational facilities and equipment we use should always check the good and the bad, the right and the wrong, the advantages and the disadvantages.

\section{Literature Review}

With the rapid development of science and technology, people's ability to use new technology in education has improved, and the research on educational facilities and equipment has become abundant. Meanwhile, the ethical reflection on educational facilities and equipment has become an important topic in academia. Searching on CNKI (China National Knowledge Infrastructure) with the theme of "ethics of educational technology", there were 245 articles published in China from 1985 to March 2021. During this period, there were only two related research documents found in CNKI. Obviously, the studies on the application of high technology in the field of education in Chinese academic circles at present are generally concerned with technology. Researchers seldom pay attention to the ethical issues and problems in the application of tools. In the Web of Science, a fuzzy search was conducted with the theme of "educational facilities and equipment plus ethics, and 501 articles were obtained among which there are ethical reflections on the application of artificial intelligence, information technology and other technologies in the field of education. There are also some ethical reflections on specific educational facilities and equipment such as tablet computers. Based on these data found from the above sources, the analysis shows that that the existing research results of educational facilities and equipment can be concluded as follows.

The imbalance of education between regions has intensified. At present, the supremacy of new technology related with educational facilities and equipment has increased the exclusiveness and digital gap of distance education [1]. For example, the opening of robotics course will lead to the imbalance of educational resources, which will become the cradle of a new round of class solidification [2]. Meanwhile, it is difficult to solve the problem of this digital gap by technological progress, financial input, and policy inclination [3].

Frequent security violations occurred. Unclear technology application boundaries may lead to security violations, for example, the application of big data in education may violate students' freedom, and the smart campus of the material 
internet campus may lead to the leakage of students' privacy.

The positions of teachers and students are weakened. Abuse of technical classroom will cause alienation of classroom, which leads to means-over-ends or facilities dominating educative purpose in teaching. Excessive application of big data in education is an overstepping of the instrumental value of data to the value of educating people [4]. Application of brain-computer interface technology as educational assistance has had negative impacts on learners' self-identity and educational communication [5].

Among the research literatures related to this topic, there are several influential studies pointing to the areas of ethics of educational equipment [6], difficulties educators face to call for intelligent educational equipment standardization in China [7], the questions need be deeply asked as to why educational facilities and equipment exist at all [8]. Further critical reflections are raised to analyze the values with caution for establishing such standardization [9]. Of course, positive voices are appraising the achievement for increasingly input by government in the field of educational technology and equipment [10], and similar judgement can be heard on the national strategic forum which gives high assessment on new technologies of innovative educational equipment [11]. In the circle of doctoral students, some are starting to write on the information technology curriculum viewed from new perspective of cultural orientation [12]. Standing on behalf of the official side, scholars are trying to explore the proper methods and coordinated development of educational equipment and higher education with Chinese characteristics [13].

To sum up, the research on ethics of educational facilities and equipment has emerged. However, the theoretical discussion is still focusing on educational technology, and the empirical research is lacking. Ethical reflection through concrete investigation data, case analysis based on practical conditions needs further studies.

\section{Problems and Countermeasures}

Update iteration of tools promotes human development and civilization. Paying attention to the updating iteration of facilities and equipment is undoubtedly one of the important means to advance the reform of education and teaching. But the problems and barriers are faced in everyday practice in schools and related sectors.

There is a lack of effective communication between the school and facilities and equipment enterprises. Supplies of facilities and equipment are lack of a proper mechanism to judge whether their products are suitable before entering schools. This causes a blind spot between the enterprises and schools choosing the products and manufacturers as suppliers.

Product enterprises of facilities and equipment are inconsistent with the goals of schools. The former is not deeply integrated with education and teaching. They incline to fucus more on products per se, thinking less on management and application. Many types of equipment are cumbersome for students and teachers to operate easily.

Facilities and equipment lack necessary ethical rationales.
The appropriateness and rationality of facilities and equipment application need to be considered. Some of them lack the necessary privacy protection for teachers and students. When artificial intelligence is widely used in education and teaching, it ignores individual privacy and violates students' growth.

The research and development of facilities and equipment lacks guidance. The uncontrolled growth of enterprises cannot secure quality guaranty for the products. As a result, educational facilities and equipment are not good enough to cover all the school disciplines at all levels. The products of mental care and special education need to be improved.

To solve the above problems, the countermeasures are needed to give life to educational facilities and equipment. The core for solving these problems is to make educational facilities and equipment from the cold to the warm, and to give warm cares to students and schools.

It is important to build a communication bridge between enterprises and schools. The administration sector responsible for educational facilities and equipment should take the lead, and cooperates with schools, research institutions, universities and enterprises should establish a fit mechanism for suitability, provide feedbacks of equipment usage on a dynamic basis and establish an information base together with the market supervision department to provide reference and comparison for schools. Schools should be provided guidelines to choose the most suitable equipment, and relevant enterprises also need such guidance to conduct research for developing products based on real needs.

Educational facilities and equipment should conform to the circumstances of teachers and students so that teachers are willing to use educational facilities and equipment heartedly. It is my opinion that we might start from the following aspects. On the one hand, the application of equipment should be made as convenient as possible to simplify cumbersome and let equipment to go back to its original nature without losing intelligence. This will help teachers get started with ease. On the other hand, it is necessary to strengthen the training of teachers' ability for using educational facilities and equipment, cultivate teachers' innovative awareness of equipment application, and at the same time establish a curriculum resource system adapted to equipment, to make equipment truly targeted purposefully, thus promoting the organic integration of space, curriculum, and technology. In short, we need to build an adaptive curriculum system, all of which are for teachers to make better use of educational facilities and equipment, reducing teachers' burdens and improve their teaching quality. The ideal educational facilities and equipment should optimize the behavior of teachers' teaching and students' learning, getting twice the result with half the effort.

Educational facilities and equipment should take the role of service for education and teaching as the goal-oriented for the appropriateness in teaching and learning. The newly developed educational facilities and equipment should support and assist education and teaching in a better way. The material things should be in the role for meaningful purposes to cultivate young people's true nature, rather than monitoring them.

Educational facilities and equipment should cover all 
grades and all disciplines and sections in schools. The existing educational facilities and equipment are mainly oriented to mainstream subjects. In recent years, the application of educational facilities and equipment serve less on students with needs in mental difficulties and urgent needs in the areas of special education, for example, in the case of insufficient consulting service teachers. The final judgement is whether cutting-edge equipment can be properly introduced to assist teachers and students in psychotherapy, answer questions for them, and sooth their emotions.

\section{Conclusion}

To conclude the topic for reflecting critically on the ethically cared facilities and equipment for school and children, it is imperative that we must make a transition from the cold to the warm in the concern of educational facilities and equipment and make a deep integration of space, curriculum, and technology of equipment.

Educational facilities and equipment advance with the development of science and technology. New educational equipment has been used in education and teaching which will not bring benefits unless we make sure to avoid potential risks and ethical problems caused by new educational equipment without purposeful significance for school children. These new educational problems cannot be ignored. Only by solving these problems can the new educational technology and equipment promote the high quality and balanced development of schools.

In theoretical sense, the studies of this topic should select ethical issues as a core focus. For schools, it is related not only to the development quality of basic education, but also to the healthy growth of each student's growth physically and mentally. This has becoming urgent when we see youngsters end their lives because of troubles caused technically. Ethical issues of new educational technology and equipment are the focus of this concern in the field of ethics. Through further in-depth analysis, combining abstract ethical values with practical problems in the process of education we will help enrich the research content of ethical issues and broaden the research horizon of ethical theory.

It is our belief that the ethic significance weighs more than the advanced use of new facilities and equipment in education. And the substantial development in technology does not necessarily secure a healthy growth of school and children. With this ethic-first value in mind, an advocacy is needed to remind people in educational communities not to regard material stuff as a foremost choice in the call for improve the quality of education and teaching. Rather, a humanist value should become the first consideration. History well manifested this conclusion when techniques did not exist at all for teachers and students. However, masters in various areas were fostered without assistance facilitated by equipment in the sense of today's criteria. The designers and producers should reflect with a warm heart on ethical issues for schools and children than the cold sophisticated development on the technical side.

\section{Acknowledgements}

Sincere thanks go to Guangzhou Institute of Educational Research for supporting the Policy Research Project: Ethic Issues of and Countermeasures to the Application of New Educational Equipment in Basic Education (ZCYJ2144). This article is part of the outcome for this project.

\section{References}

[1] Zhao Yi, Yu Yuhua, Shang Zhe. Rational thinking on the application of new technology in modern distance education. Journal of Hebei Normal University-Educational Science Edition, 2009, 11 (09): 139-141.

[2] An Li, Liu Jun. Research on the trend of class solidification under the imbalance of quality education resources Taking the robot course teaching in Jinghu District of Wuhu City as an example. Public Relations World, 2021 (04): 71-74.

[3] Li Zhiming. Ethical reflection and resolution of campus technology application. Modern Educational Science, 2017 (06): 110-116.

[4] Zhang Jiangkun. Ethics of big data education application. (Mater Thesis, Shandong Normal University, 2019).

[5] Zhu Hongyang. Learning phantom limb and panoramic vision of nerve: the main ethical challenge of applying brain-computer interface technology to education. Audio-visual Education Research, 2020, 41 (05): 39-44.

[6] Allen (2021). Ethics of Educational Equipment. China modern educational equipment (04), 11-16.

[7] Allen (2021). Dilemma of intelligent educational equipment standardization in China. China modern educational equipment (02), 12-16.

[8] Allen (2020). the existence value of educational equipment. China modern educational equipment (20), 1-7.

[9] Zhang Yaodong. (2017). Value analysis and promotion strategy suggestions of strengthening the standardization of educational equipment under the new situation. Education and Equipment Research (01), 12-16.

[10] Zhao Xiaoning, Xin Qiao \& Ren Xijun. (2018). Giving priority to the development of education and continuously increasing investment in education-a great achievement in the development of educational technology and equipment. China's educational technology and equipment (14), 1-5.

[11] Shi Jianguo. (2014). Speech at the strategic Forum on Leading Ten New Technologies of Educational Equipment-Innovation of Basic Educational Technology Equipment Work and Educational Modernization. Teaching Instruments and Experiments (01), 3-7.

[12] Qian Xusheng. (2008). Research on the cultural orientation of information technology curriculum implementation (doctoral dissertation, Southwest University).

[13] Gong Wenqing. (2010). Exploring the methods and modes for the coordinated development of modern educational equipment and higher vocational education with Chinese characteristics. China modern educational equipment (22), 3-4. 